\title{
Periodontal condition of mandibular incisors treated with modified Kazanjian vestibuloplasty compared to untreated sites: A prospective study
}

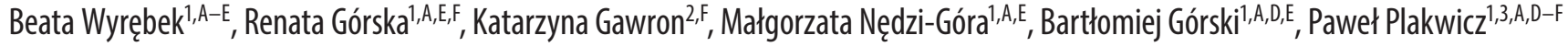 \\ ${ }^{1}$ Department of Periodontology, Medical University of Warsaw, Poland \\ ${ }^{2}$ Department of Molecular Biology and Genetics, Medical University of Silesia, Katowice, Poland \\ ${ }^{3}$ Chair and Department of Periodontology, Medical University of Lublin, Poland \\ A - research concept and design; $\mathrm{B}$ - collection and/or assembly of data; $\mathrm{C}$ - data analysis and interpretation; \\ $\mathrm{D}$ - writing the article; $\mathrm{E}$ - critical revision of the article; $\mathrm{F}$ - final approval of the article
}

\section{Address for correspondence}

Beata Wyrębek

Email: beatawyrebek@gmail.com

Funding sources

None declared

Conflict of interest

None declared

Received on August 10, 2020

Reviewed on November 28, 2020

Accepted on February 19, 2021

Published online on June 11, 2021

Cite as

Wyrębek B, Górska R, Gawron K, Nędzi-Góra M, Górski B, Plakwicz P. Periodontal condition of mandibular incisors treated with modified Kazanjian vestibuloplasty compared to untreated sites: A prospective study. Adv Clin Exp Med. 2021;30(7):681-690. doi:10.17219/acem/133492

DOI

10.17219/acem/133492

Copyright

Copyright by Author(s)

This is an article distributed under the terms of the

Creative Commons Attribution 3.0 Unported (CC BY 3.0)

(https://creativecommons.org/licenses/by/3.0/)

\begin{abstract}
Background. A shallow vestibule, insufficient keratinized tissue width and pulling of marginal gingiva may be associated with gingival recession, plaque accumulation and gingivitis. Conventional techniques for treatment of gingival recession use autogenous or allogenic grafts. However, these methods result in soreness at the donor site and pose an economic burden, which may cause patients to withdraw from treatment. Alternative therapy is currently not available to treat such patients.

Objectives. The aim of this study was to evaluate changes in periodontal tissue at the mandibular incisors after vestibuloplasty, focusing on functional improvement of the existing soft tissue with no grafting.

Materials and methods. Thirty patients with a shallow vestibule, minimal keratinized tissue width (KTW; $\leq 1 \mathrm{~mm}$ ), gingival recession (REC) and pulling of gingiva underwent modified Kazanjian vestibuloplasty were included into the test group, whereas 27 patients did not undergo any surgery (control group). The probing pocket depth (PPD), clinical attachment level (CAL), gingival recession depth (GRD), and KTW were assessed at baseline and 12 months post-surgery.

Results. The mean KTW, GRD and CAL values improved in the test group. A significant increase in mean KTW value $(1.17 \pm 1.22 \mathrm{~mm}, p=0.0406)$ was detected in the test group, while the control group showed a further reduction in mean $K T W$ value $(0.13 \pm 0.45 \mathrm{~mm})$. The mean GRD value decreased from $2.09 \pm 1.78 \mathrm{~mm}$ to $1.22 \pm 1.46 \mathrm{~mm}(p=0.0087)$ in the test group, whereas in controls the mean GRD value increased from $1.95 \pm 1.29 \mathrm{~mm}$ to $2.34 \pm 1.44 \mathrm{~mm}$ ( $p=0.0164$ ). The mean KTW value at 3, 6 and 12 months compared to baseline showed an increase in the test group, and the mean GRD and CAL values exhibited the potential to improve.
\end{abstract}

Conclusions. Sites treated with vestibuloplasty showed increased KTW, improvement in the gingival margin and CAL gain, whereas untreated sites showed continuous deterioration of the evaluated parameters. Vestibuloplasty may be recommended for patients avoiding major surgery for which functional improvement in tissue alone would provide a sufficient therapeutic outcome.

Key words: gingival recession, keratinized tissue, vestibuloplasty 


\section{Background}

A shallow vestibule in the anterior region of the lower dental arch may impede proper oral hygiene due to insufficient space for the toothbrush, leading to plaque accumulation and traumatizing brushing technique. It can result in marginal gingivitis and the potential for the occurrence or exacerbation of gingival recessions. Moreover, a shallow vestibule often coexists with a narrow zone of keratinized gingiva and attached gingiva or frena attachment with pulling of the gingival margin. Measurement of vestibule depth is not commonly performed in a standard periodontal examination. There are no established methods to measure the depth of the vestibule or reference values to classify its type, which is commonly categorized as shallow or deep. ${ }^{1-3}$ According to Ward, the depth of the vestibular fornix in the lower anterior region, measured from the gingiva to the mucobuccal fold, varies from $2.5 \mathrm{~mm}$ to $11.5 \mathrm{~mm} .{ }^{4}$ In patients with excellent dental plaque control, periodontal health can be preserved in spite of lack of keratinized tissue. Conversely, in cases with suboptimal plaque removal, a thin periodontal phenotype requiring restorative, orthodontic or prosthetic treatment and deficiency of keratinized tissue may be associated with gingival recession and inflammation. As a result, coexisting esthetic impairment, dentin hypersensitivity, discomfort during tooth brushing, root caries, and non-carious cervical lesions may be a cause for concern in both patients and clinicians. Especially in the mandibular incisor region, other factors such as the presence of frena attachment, muscle pull and a shallow fornix may predispose a patient to future soft tissue loss in case of inadequate plaque control and lack of keratinized tissue. ${ }^{5}$ A long-standing debate in the scientific community relates to the optimal amount of keratinized tissue. It is agreed that $\geq 2 \mathrm{~mm}$ of keratinized tissue and $\geq 1 \mathrm{~mm}$ of attached gingiva is beneficial around teeth to maintain periodontal health. ${ }^{6}$

Various techniques for deepening the vestibule have been described; however, most of them are not used due to postsurgical complications that result from exposing a varying area of the crestal bone. ${ }^{1,7-10}$ Surgical methods of deepening the oral vestibule, besides vestibuloplasty procedures, include autogenic soft tissue grafting. ${ }^{5,6,11}$ Deepening the oral vestibule can enable maintenance of proper oral hygiene, remove improper attachment of the lower lip frenulum and eliminate pulling of the gingival margin. If soft tissue grafting is used to deepen the vestibule, an additional effect is obtained, namely widening the keratinized gingival zone and covering or decreasing the existing recessions. However, insufficient thickness of palatal tissue at the donor site, or patient refusal of grafting, effectively prevents palatal tissue graft surgery in a considerable number of patients.

Kazanjian described a less invasive technique in which a split-thickness flap is prepared. ${ }^{12}$ Kazanjian vestibuloplasty was originally performed before prosthetic treatment to reposition the mucosa and muscle insertions and to increase the denture area for stability of the prosthesis. Individual studies have described the positive effects of vestibular deepening performed without grafts on periodontal tissue parameters and oral hygiene in dentate segments. ${ }^{13,14}$ To overcome some postoperative complications associated with the Kazanjian technique, several modifications have been suggested by other authors ${ }^{15-17}$ as well as in our work. ${ }^{14,18}$

Nevertheless, autogenous tissue grafts are still considered the gold standard for soft tissue augmentation and provide unparalleled outcomes in terms of clinical improvement. ${ }^{5,6,19}$ However, free gingival grafts (FGG) may be associated with patient morbidity at the donor site and poor color blending with neighboring tissues. Presently, alternative commercially available materials may partially compensate for the drawbacks of FGG, since they provide significant improvements in matching the color and texture of keratinized tissue. Moreover, graft substitutes do not require graft harvesting from a second surgical site. Autogenous soft tissue grafts can be harvested from the palate or maxillary tuberosity using different approaches, such as the trap-door technique, single incision technique, parallel incision technique, and de-epithelialization technique. ${ }^{20-22}$ A second surgical site and prolonged surgical time are correlated with greater postoperative pain and swelling. ${ }^{6}$ Moreover, in some cases, the thickness of the palatal mucosa can constitute an additional limiting factor.

There is unprecedented interest in graft substitutes, which can be divided into allogenic, xenogenic, alloplastic, and living constructs. Unrestricted availability, avoidance of a secondary surgical site, reduced surgical time, and decreased patient morbidity are some of the major benefits of these materials. Acellular dermal matrix (ADM), ${ }^{23}$ Mucograft (Geistlich Pharma, Wolhusen, Switzerland) ${ }^{24,25}$ and DynaMatrix (Keystone Dental, Burlington, USA) ${ }^{26}$ are examples of commercially available materials. Overall, there is evidence in the literature that graft substitutes are effective in augmenting keratinized tissue in an esthetically pleasing way. However, at present, there is not enough evidence to support or refute the superiority of any particular product. It is also important to highlight that FGG and bilaminar approaches lead to superior outcomes in terms of mean keratinized tissue width (KTW) gain.

The labial surfaces of mandibular incisors are commonly affected by inadequate KTW volume, the presence of frena attachment, muscle pull, and gingival recessions. Since the tooth germs of lateral incisors are situated more lingually with respect to the central incisors, the former teeth are more often associated with periodontal problems. ${ }^{27}$ Less traumatic procedures that involve only 1 surgical site, require less chair time and provide an optimal costto-benefit ratio for improving periodontal condition are still needed. Kazanjian vestibuloplasty seems to represent an alternative and functional approach to more advanced grafting techniques, especially for patients who do not want or cannot have (due to palate soft tissue condition) conventional treatment. 


\section{Objectives}

The aim of this study was to evaluate changes in periodontal tissue at lower incisors with a lack of keratinized tissue, muscle pull and gingival recessions 12 months after modified Kazanjian vestibuloplasty, compared to untreated sites.

\section{Materials and methods}

\section{Study design and patient population}

This study was planned as a prospective, non-randomized, parallel trial (Fig. 1). The investigator who evaluated the clinical outcomes was not aware of the treatment protocol. Patients in the test group underwent vestibuloplasty in the anterior region of the mandible, whereas patients in the control group did not undergo any surgical treatment. The study design and all clinical procedures were performed in accordance with the Helsinki Declaration of 1975, as revised in Tokyo in 2004, after approval of the study protocol by the Bioethics Committee of the Medical University of Warsaw, Poland (approval
No. AKBE/106/15). Participants were recruited among patients referred to the Department of Periodontology and Oral Mucosa Diseases at the Medical University of Warsaw by their general dentists between January 2013 and December 2015 due to decreased vestibular depth, pulling of the gingival margin, narrow keratinized gingiva, single or multiple gingival recessions, or an aberrant frenum position in the area of the lower anterior teeth. One examiner (M.N-G.) qualified patients into the study. All patients were informed about all plausible treatment options, including soft tissue augmentation with either autogenous soft tissue graft or collagen matrix, as well as modified vestibuloplasty according to the Kazanjian method. Patients who declined soft tissue augmentation but allowed vestibuloplasty, together with patients who decided not to receive any surgery at all, were enrolled in the study. Patients were thoroughly informed of the nature of the study and the potential risks and benefits of their participation. All patients signed an informed consent form. Subsequently, patients were meticulously instructed on how to use the roll technique with a soft toothbrush and provided with a professional full-mouth cleaning and polishing.

Fifty-seven patients ( 45 women and 12 men, aged $21-56$; mean age $37.58 \pm 6.11$ years) participated in this

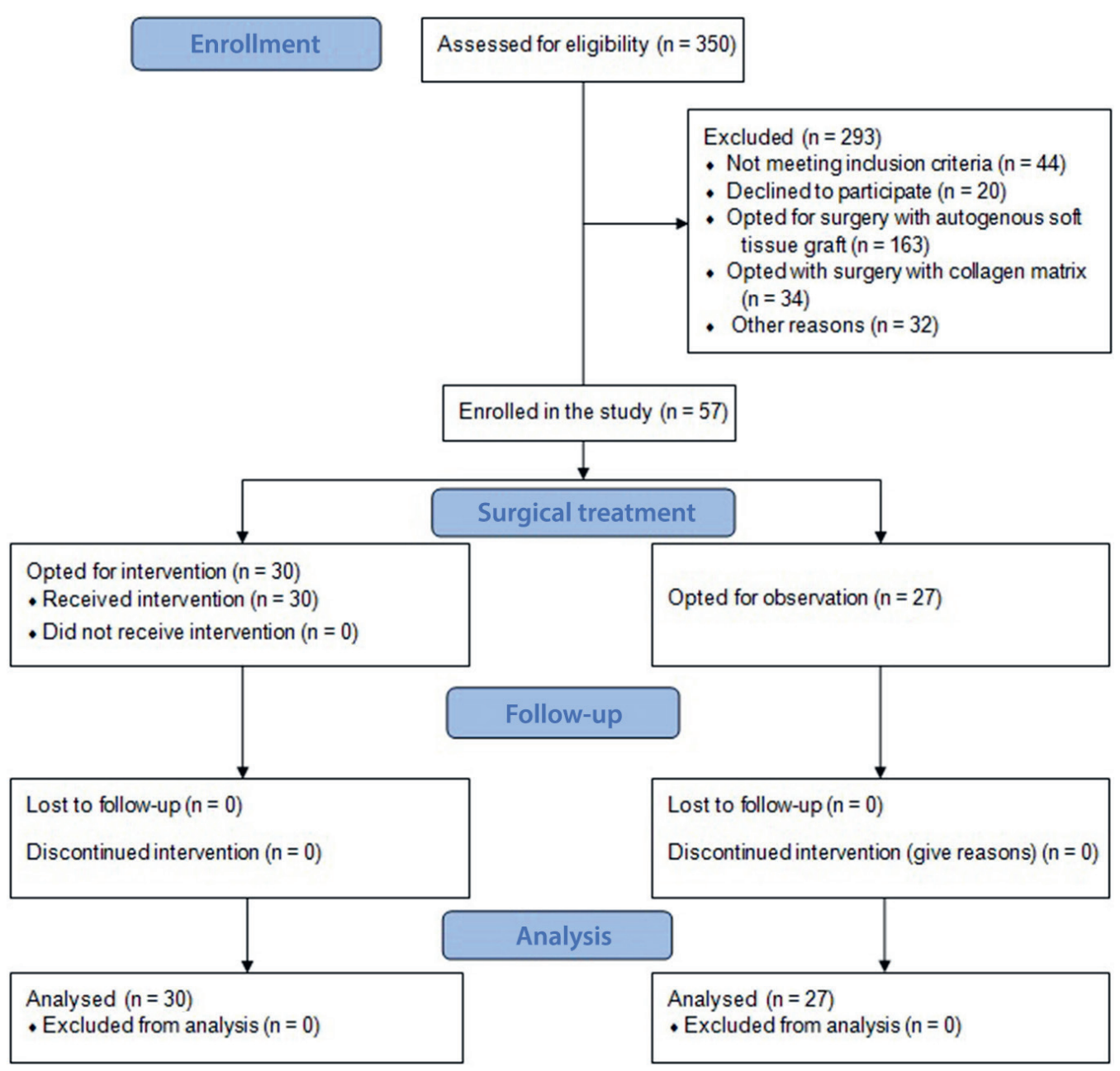

Fig. 1. Diagram showing the study design 
study, of which 30 patients underwent modified Kazanjian vestibuloplasty (test group). The control group consisted of 27 patients (20 women and 7 men, aged $24-54$, mean age $39.13 \pm 5.62$ years) who declined any surgical treatment but agreed to a 12-month observation.

\section{Inclusion and exclusion criteria}

The following inclusion criteria were applied: 1) a shallow vestibule, muscle pull, frena attachment with pull syndrome, and at least q lower incisor with KTW $\leq 1 \mathrm{~mm}$ in the apico-coronal dimension; 2) full mouth plaque score (FMPS) $\leq 20 \%$; 3 ) full mouth bleeding on probing score (FMBOP) $\leq 20 \%$; 4) no active gingivitis or periodontitis; $5)$ over 18 years of age; 6) no systemic disease with compromised healing potential; 7) no intake of medications affecting periodontal status; 8) no smoking; 9) no pregnant or lactating women; and 10) no previous periodontal plastic surgery in the anterior mandible.

\section{Clinical measurements}

Clinical parameters were evaluated by 1 experienced examiner (BW). A total of 5 patients with gingival recessions on the buccal surfaces of the lower incisors were recruited for the calibration exercise. The examiner recorded the periodontal parameters in the mandible with an interval of $24 \mathrm{~h}$ between measurements. Calibration was accepted when $\geq 90 \%$ of the recorded values were reproduced within a difference of $1.0 \mathrm{~mm}$ and exact data were reported in $75 \%$ of measurements. The following parameters were assessed using a graded periodontal probe (UNC probe $15 \mathrm{~mm}$; Hu-Friedy, Chicago, USA): 1) probing pocket depth (PPD), distance from the gingival margin to the bottom of the gingival sulcus at 6 points per tooth (mesio-buccal (MB), mid-buccal (B), disto-buccal (DB), mesio-lingual (MD), mid-lingual (ML), and disto-lingual (DL)); 2) clinical attachment level (CAL), distance from the cementoenamel junction (CEJ) to the bottom of the gingival sulcus at 6 points per tooth $(\mathrm{MB}, \mathrm{B}, \mathrm{DB}, \mathrm{ML}, \mathrm{L}$, and $\mathrm{DL})$; 3) gingival recession depth (GRD), distance from CEJ to the most apical extension of the gingival margin at the mid-buccal point of the tooth; 4) KTW, the distance between the most apical point of the gingival margin and the mucogingival junction (MGJ), with the MGJ demarcated by staining the mucogingival complex with iodine solution; 5) FMPS, the percentage of total surfaces ( 4 aspects per tooth) that revealed the presence of plaque ${ }^{28}$; and 6) FMBOP, assessed dichotomously at 6 points per tooth $(\mathrm{MB}, \mathrm{B}, \mathrm{DB}$, $\mathrm{ML}, \mathrm{L}$, and $\mathrm{DL}$ ) as the percentage of bleeding points. ${ }^{29}$ The GRD was classified according to the Miller classification (Class I - GRD does not extend to MGJ and there is no loss of interdental bone and soft tissue; Class II - GRD extends to or beyond MGJ and there is no loss of interdental bone and soft tissue; Class III - GRD extends to or beyond MGJ with alveolar bone and soft tissue loss in the interdental area; and Class IV - GRD extends to or beyond MGJ with severe alveolar bone and soft tissue loss in the interdental area) and in line with the Cairo classification (RT1 - GRD with no loss of interproximal attachment; RT2 - the amount of interproximal attachment loss is equal to or lower than the buccal attachment loss; and RT3 - the amount of interproximal attachment is greater than the buccal attachment loss). ${ }^{30,31}$ In the test group, clinical parameters were recorded at baseline and at 3, 6 and 12 months postoperatively. In the control group, clinical parameters were assessed at baseline and 12 months after baseline examination.

\section{Surgical treatment}

For the test group, the surgical procedures were performed by 1 experienced surgeon (P.P.) in accordance with modified Kazanjian vestibuloplasty under local anesthesia with $4 \%$ articaine hydrochloride with adrenaline (1:100,000) (Ubistesin Forte $1.7 \mathrm{~mL}$; 3M ESPE, Saint Paul, USA). A single horizontal incision was made with a scalpel blade from the lower right canine to the lower left canine within the mucosa of the inner part of the lip, 9-12 $\mathrm{mm}$ from the mucogingival junction. A split-thickness pedicle flap was prepared with its base on the alveolar part of the mandible to the level of the keratinized gingiva. The muscle attachments beneath the free margin of the flap were separated and moved apically. The remnants of muscle tissue were removed from the periosteum on the vestibular part of the anterior mandible. Limited flap preparation and only small correction of submucosal tissue constituted modifications of the original technique. The mobilized flap was then stabilized apically with resorbable single sutures (PGA Resorba 6/0 $11 \mathrm{~mm}$, 3/8; RESORBA Medical GmbH, Nuremburg, Germany) to the underlying periosteum at the level of the newly established vestibular depth (Fig. 2). The area on the inner surface of the lower lip was left to heal by secondary intention.

\section{Postoperative period}

After surgery, patients received $800 \mathrm{mg}$ of ibuprofen and were asked to take a $2^{\text {nd }}$ dose $8 \mathrm{~h}$ later as well as additional tablets later on if required to control postoperative pain. Patients were instructed to take azithromycin (500 mg once daily) for 3 days. Meticulous written postoperative instructions to avoid brushing, flossing and chewing in the treated area for a period of 2 weeks were handed to all subjects after surgery. Patients were asked to apply $1 \%$ chlorhexidine gel topically to the operative site and to rinse their mouth twice daily for 1 min using $0.2 \%$ chlorhexidine solution. At week 2 , the sutures were removed and patients resumed careful brushing with a soft toothbrush. Followup appointments were scheduled for 1,2 , and 4 weeks after surgery, as well as 3, 6 and 12 months after the baseline 
examination. Each session included reinforcement of oral hygiene instructions (teeth brushing with the roll technique and dental flossing twice a day) and supragingival plaque removal. Two clinical cases are shown in Fig. 2 and Fig. 3.
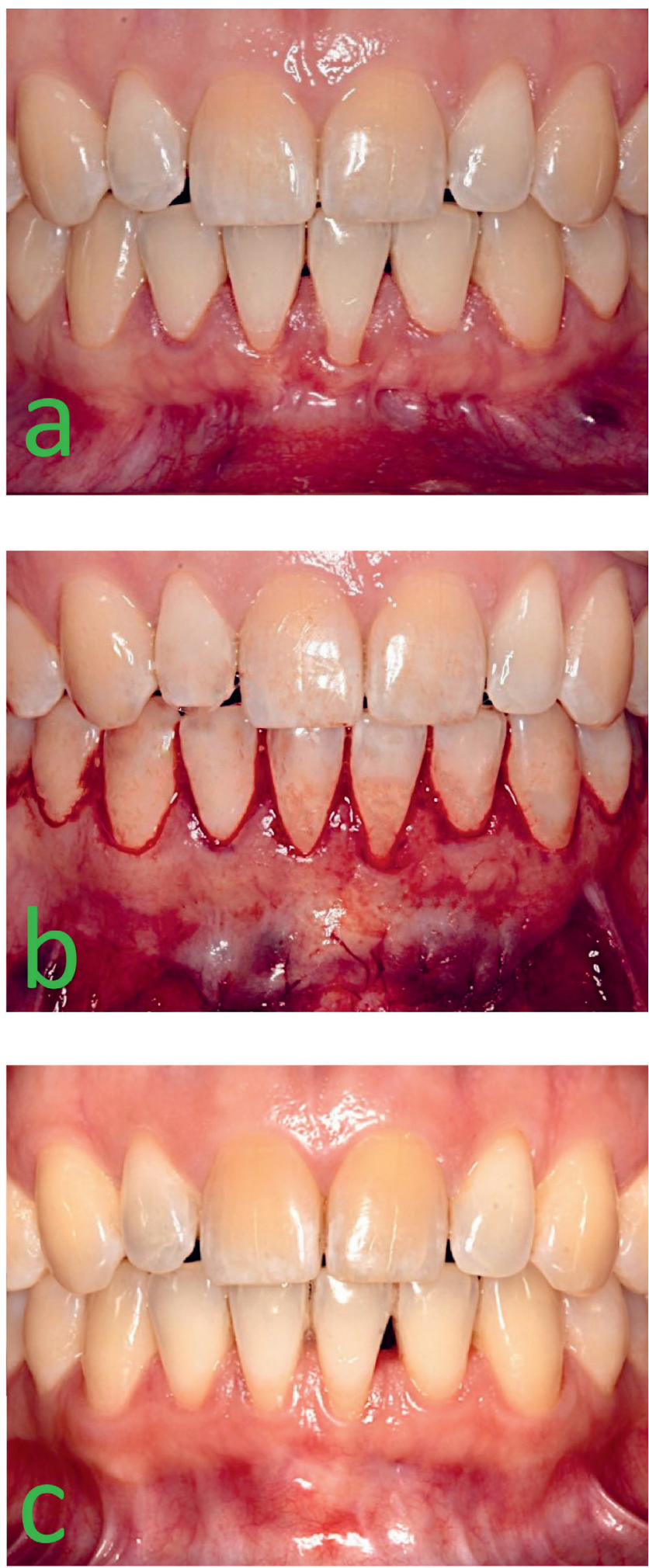

Fig. 2. A. Pre-operative view of test site; B. immediate post-operative view: C. 12 months post-operative view
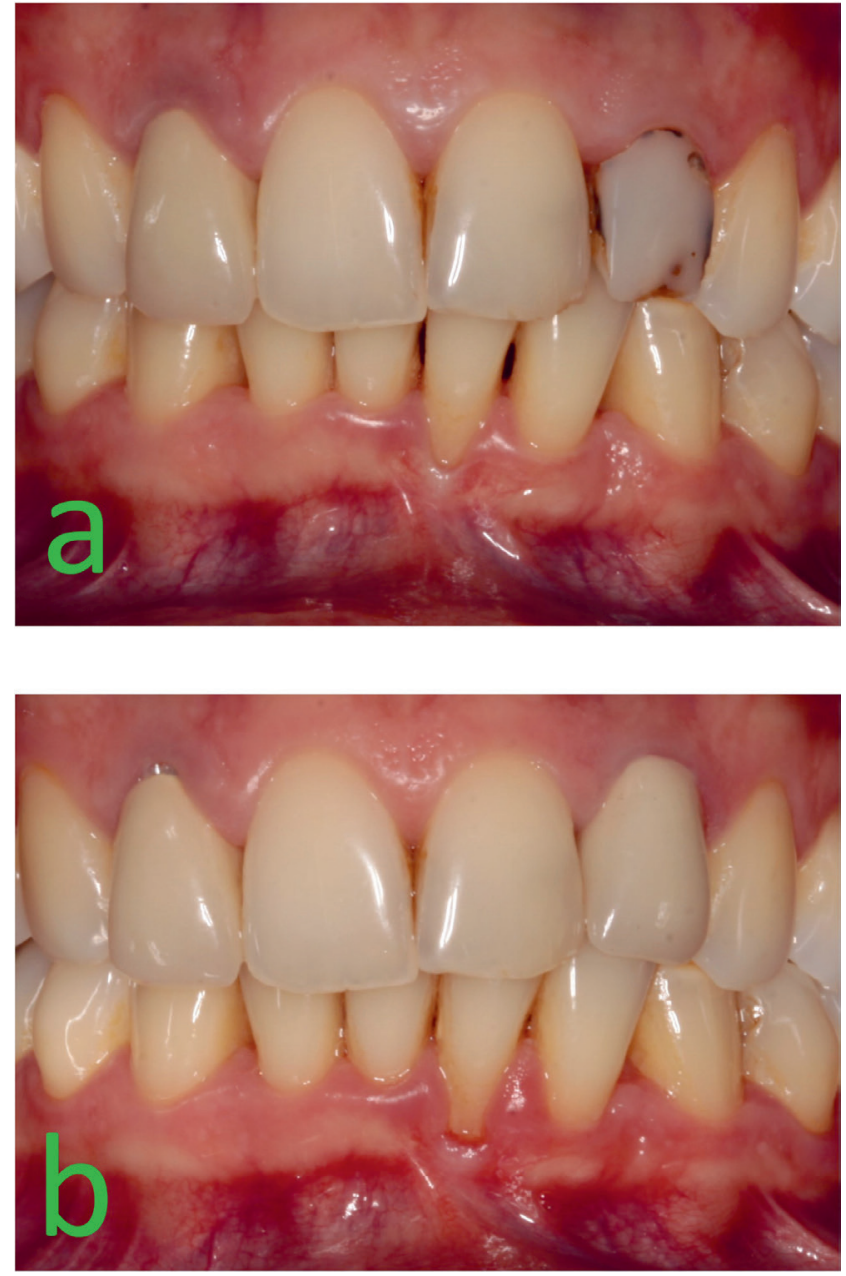

Fig. 3. A. Baseline view of control site; B. 12 months post-operative view

\section{Statistical analyses}

Statistical analyses were performed using R v. 3.2.3 software (R Core Team 2019; R Foundation for Statistical Computing, Vienna, Austria). Clinical parameters were compared between the 2 groups. The primary outcome variable was an increase in the keratinized tissue width at 12 months, and the secondary variables were gingival recession height reduction and gain in clinical attachment level at 12 months. Descriptive statistics were carried out using mean values, 95\% confidence intervals (95\% CI), standard deviations (SD), frequencies, and percentages. The Shapiro-Wilk test was used to assess data distribution normality. As all quantitative variables in this study were normally distributed, Student's t-test was applied for intragroup and intergroup comparisons. To evaluate the effectiveness of treatment, the following calculations were done: 1) KTWgain = KTW12 - KTW0; 2) gingival recession reduction $=$ GRD $0-$ GRD 12. To compare measurements at the 4 time points (baseline, 3,16 , and 12 months) in the test group, two-way analysis of variance (ANOVA) was used. Statistical significance was set at $\mathrm{p}<0.05$. 


\section{Results}

The test group included 30 patients (25 women and 5 men, aged $21-56$, mean age $36.03 \pm 6.61$ years) who underwent modified Kazanjian vestibuloplasty on the vestibular surfaces of the lower incisors. Post-surgical healing was uneventful in all patients, all of whom completed the 12-month follow-up. Hypertrophic scar formation was observed in 3 patients, while scar lines were visible in the apical regions in 5 patients. The control group consisted of 27 patients ( 20 women and 7 men, aged 24-54, mean age $39.13 \pm 5.62$ years) who declined any surgical treatment but agreed to 12 -month observation. The majority of observed labial gingival recessions at baseline in both groups were class I according to Miller and recession type 1 (RT1) according to Cairo (Table 1).

The clinical characteristics of the groups at baseline and 12-month follow-up are depicted in Table 2. With the exception of KTW, both groups had similar clinical parameters at baseline. The FMPS and FMBOP values remained low throughout the observation period. However, in the test group, we observed statistically significant improvement in local bleeding on probing score (BOP) for the treated areas as compared to controls. At the end of the study, the mean PPD value assessed at 6 points per incisor, as well as only in buccal aspects of the tooth, increased significantly in controls from $1.70 \pm 0.59$ to $1.77 \pm 0.63 \mathrm{~mm}$ and from $1.79 \pm 0.59 \mathrm{~mm}$ to $1.88 \pm 0.65 \mathrm{~mm}$, respectively. Twelve months after surgical treatment, the mean CAL, GRD and KTW values improved in the test group. At test sites the mean CAL value decreased from $2.28 \pm 1.91 \mathrm{~mm}$ to $1.63 \pm 1.66 \mathrm{~mm}(\mathrm{p}=0.3802)$, whereas at control sites the mean CAL value increased from $\mathrm{mm} 1.86 \pm 1.63 \mathrm{~mm}$ to $2.07 \pm 1.79 \mathrm{~mm}(\mathrm{p}=0.2292)$. The statistical significance of the changes in CAL measured at the mid-buccal point of the teeth is presented in Table 3. At test sites the mean GRD value decreased from $2.09 \pm 1.78 \mathrm{~mm}$ to $1.22 \pm 1.46 \mathrm{~mm}(\mathrm{p}=0.0087)$, whereas at control sites the mean GRD value increased from $1.95 \pm 1.29 \mathrm{~mm}$ to $2.34 \pm 1.44 \mathrm{~mm}(\mathrm{p}=0.0164)$. Surgical treatment resulted in a significant increase in the mean KTW value

Table 1. Baseline characteristics of the test and control groups with respect to gingival recession

\begin{tabular}{|l|c|c|}
\multicolumn{1}{|c|}{ Variables } & $\begin{array}{c}\text { Test group } \\
(\mathrm{N}=30)\end{array}$ & $\begin{array}{c}\text { Control group } \\
(\mathrm{N}=27)\end{array}$ \\
\hline \begin{tabular}{l|l} 
Class of GRD according to Miller ( $\mathrm{n})$ \\
Class I
\end{tabular} & 57 & 63 \\
Class II & 24 & 22 \\
Class III & 10 & 7 \\
Class IV & 0 & 0 \\
\hline Type of GRD according to Cairo (n) & & \\
RT1 & 76 & 78 \\
RT2 & 13 & 3 \\
RT3 & 2 & 11 \\
\hline
\end{tabular}

$\mathrm{N}$ - number of patients; $\mathrm{n}$ - number of defects; GRD - gingival recession depth; RT - recession type.
$(1.17 \pm 1.22 \mathrm{~mm}, \mathrm{p}=0.0406)$ in the test group. By contrast, in the control group, further reduction in the mean $\mathrm{KTW}$ value to $0.13 \pm 0.45 \mathrm{~mm}$ was observed. The mean KTW value at 3, 6 and 12 months compared to baseline showed a tendency to increase in the test group (Table 3). The relative mean GRD values exhibited the potential to decrease over time. From baseline to 12 months, there were statistically significant increases in mean CAL and KTW, as well as significant GRD reduction, for the mid-buccal aspects of the lower incisors in the test group. No changes were observed in terms of the mean PPD value.

\section{Discussion}

A poor mucogingival condition is common in the lower incisor area. In case of inadequate KTW, decreased vestibular depth and muscle pull, mucogingival surgery may be performed to ease plaque control, improve patient comfort during tooth brushing, and reduce, halt or avoid gingival recession formation. Different procedures provide varying degrees of success. The present study evaluated periodontal condition at the lower incisors in patients who underwent simple vestibuloplasty versus untreated patients who served as controls. Each patient had at least 1 incisor with $\mathrm{KTW} \leq 1 \mathrm{~mm}$, gingival recession, and the presence of muscle pull or high frena attachment. To the best of our knowledge, this is the first study to compare these 2 approaches in natural teeth. At the end of the follow-up period, the test group showed significant gains in KTW and CAL (at the mid-buccal point) and reduction in GRD, which improved continuously during the observation period. The KTW increased by $1.17 \mathrm{~mm}$. In the control group, the abovementioned parameters worsened over time, together with significant increases in PPD, as a result of impaired plaque control at the affected sites. Our study suggests that modified Kazanjian vestibuloplasty is associated with more stable periodontal tissue compared to untreated sites. This procedure has the benefits of simplicity, less time required, no need for a second surgical site (which lowers morbidity), and an esthetically pleasing tissue match. It may be an alternative approach in case of patients who want to avoid major surgery and for whom functional improvement of periodontal soft tissues alone will bring a sufficient treatment outcome.

Our findings also indicate that, apart from the expected vestibular deepening, it is possible to obtain the additional effect of reducing existing recessions where the vestibule is shallow. One has to bear in mind, however, that the main objective of vestibuloplasty is not coverage of recessions but elimination of recession-inducing factors. It has been argued that FGG should be considered the first and the most effective choice for increasing developmentally missing or lost keratinized tissue and may eliminate muscle pull. Agudio et al. evaluated changes in the amount of keratinized tissue in 103 patients treated 
Table 2. Clinical parameters (mean, 95\% Cl, SD) at the lower incisors at baseline and after 12 months

\begin{tabular}{|c|c|c|c|}
\hline Variables & Baseline & 12 months & $\mathrm{p}$-value \\
\hline $\begin{array}{l}\text { PPD tests }[\mathrm{mm}] \\
\text { PPD controls }[\mathrm{mm}] \\
\text { \#p-value }\end{array}$ & $\begin{array}{c}1.69[1.64 ; 1.74] \pm 0.69 \\
1.70[1.65 ; 1.74] \pm 0.59 \\
0.4324\end{array}$ & $\begin{array}{c}1.70[1.65 ; 1.75] \pm 0.69 \\
1.77[1.72 ; 1.82] \pm 0.63 \\
0.0398^{*}\end{array}$ & $\begin{array}{c}0.5032 \\
0.0332^{*}\end{array}$ \\
\hline $\begin{array}{l}\text { PPDb tests [mm] } \\
\text { PPDb controls [mm] } \\
\text { \#p-value }\end{array}$ & $\begin{array}{c}1.79[1.71 ; 1.87] \pm 0.74 \\
1.79[1.73 ; 1.86] \pm 0.59 \\
0.7803\end{array}$ & $\begin{array}{c}1.76[1.69 ; 1.83] \pm 0.68 \\
1.88[1.81 ; 1.95] \pm 0.65 \\
0.0065^{*}\end{array}$ & $\begin{array}{c}0.3503 \\
0.0229^{*}\end{array}$ \\
\hline $\begin{array}{l}\text { CAL tests }[\mathrm{mm}] \\
\text { CAL controls }[\mathrm{mm}] \\
\text { \#p-value }\end{array}$ & $\begin{array}{c}1.79[1.66 ; 1.92] \pm 1.77 \\
1.37[1.26 ; 1.48] \pm 1.46 \\
0.8932\end{array}$ & $\begin{array}{c}1.38[1.26 ; 1.50] \pm 1.58 \\
1.49[1.37 ; 1.61] \pm 1.57 \\
0.903\end{array}$ & $\begin{array}{l}0.6764 \\
0.7018\end{array}$ \\
\hline $\begin{array}{l}\text { CALb tests }[\mathrm{mm}] \\
\text { CALb controls }[\mathrm{mm}] \\
\text { \#p-value }\end{array}$ & $\begin{array}{c}20.28[1.69 ; 1.83] \pm 1.91 \\
10.86[1.68 ; 2.04] \pm 1.63 \\
0.2765\end{array}$ & $\begin{array}{c}1.63[1.45 ; 1.80] \pm 1.66 \\
2.07[1.87 ; 2.27] \pm 1.79 \\
0.3007\end{array}$ & $\begin{array}{l}0.3802 \\
0.2292\end{array}$ \\
\hline $\begin{array}{l}\text { GRD tests }[\mathrm{mm}] \\
\text { GRD controls }[\mathrm{mm}] \\
\text { \#p-value }\end{array}$ & $\begin{array}{c}2.09[1.76 ; 2.41] \pm 1.78 \\
1.95[1.70 ; 2.20] \pm 1.29 \\
0.6320\end{array}$ & $\begin{array}{c}1.22[0.95 ; 1.48] \pm 1.46 \\
2.34[2.06 ; 2.61] \pm 1.44 \\
0.0421^{*}\end{array}$ & $\begin{array}{l}0.0087^{*} \\
0.0164^{*}\end{array}$ \\
\hline $\begin{array}{l}\text { GRD red tests [mm] } \\
\text { GRD red controls [mm] } \\
\text { \#p-value }\end{array}$ & - & $\begin{array}{c}0.85[0.67 ; 1.04] \pm 1.04 \\
-0.38[-0.51 ;-0.24] \pm 0.69 \\
0.2139\end{array}$ & - \\
\hline $\begin{array}{l}\text { KTW tests [mm] } \\
\text { KTW controls [mm] } \\
\text { \#p-value }\end{array}$ & $\begin{array}{c}2.24[2.05 ; 2.43] \pm 1.06 \\
1.77[1.62 ; 1.92] \pm 0.78 \\
0.0339^{*}\end{array}$ & $\begin{array}{c}3.42[3.18 ; 3.66] \pm 1.29 \\
1.64[1.48 ; 1.79] \pm 0.80 \\
0.0299^{*}\end{array}$ & $\begin{array}{c}0.0406^{*} \\
0.7002\end{array}$ \\
\hline $\begin{array}{l}\text { KTWgain tests [mm] } \\
\text { KTWgain controls [mm] } \\
\text { \#p-value }\end{array}$ & - & $\begin{array}{c}1.17[-1.40 ;-0.95] \pm 1.22 \\
-0.13[0.04 ; 0.22] \pm 0.45 \\
0.04489^{*}\end{array}$ & $\begin{array}{l}- \\
-\end{array}$ \\
\hline $\begin{array}{l}\text { FMPS tests }[\mathrm{mm}] \\
\text { FMPS controls }[\mathrm{mm}] \\
\text { \#p-value }\end{array}$ & $\begin{array}{c}0.14[0.11 ; 0.16] \pm 0.23 \\
0.20[0.16 ; 0.23] \pm 0.28 \\
0.3412\end{array}$ & $\begin{array}{c}0.13[0.10 ; 0.15] \pm 0.21 \\
0.18[0.15 ; 0.21] \pm 0.25 \\
0.2081\end{array}$ & $\begin{array}{l}0.8721 \\
0.7088\end{array}$ \\
\hline $\begin{array}{l}\text { PS tests }[\mathrm{mm}] \\
\text { PS controls [mm] } \\
\text { \#p-value }\end{array}$ & $\begin{array}{c}0.19[0.14 ; 0.23] \pm 0.26 \\
0.25[0.20 ; 0.31] \pm 0.30 \\
0.2291\end{array}$ & $\begin{array}{c}0.20[0.15 ; 0.25] \pm 0.26 \\
0.29[0.24 ; 0.35] \pm 0.26 \\
0.3010\end{array}$ & $\begin{array}{l}0.9301 \\
0.9118\end{array}$ \\
\hline $\begin{array}{l}\text { FMBOP tests }[\mathrm{mm}] \\
\text { FMBOP controls }[\mathrm{mm}] \\
\text { \#p-value }\end{array}$ & $\begin{array}{c}0.16[0.14 ; 0.18] \pm 0.21 \\
0.19[0.16 ; 0.22] \pm 0.23 \\
0.4328\end{array}$ & $\begin{array}{c}0.06[0.04 ; 0.07] \pm 0.11 \\
0.16[0.14 ; 0.19] \pm 0.20 \\
0.2281\end{array}$ & $\begin{array}{l}0.7356 \\
0.8021\end{array}$ \\
\hline $\begin{array}{l}\text { BOP tests }[\mathrm{mm}] \\
\text { BOP controls }[\mathrm{mm}] \\
\text { \#p-value }\end{array}$ & $\begin{array}{c}0.24[0.20 ; 0.29] \pm 0.24 \\
0.29[0.25 ; 0.33] \pm 0.22 \\
0.8743\end{array}$ & $\begin{array}{c}0.07[0.05 ; 0.09] \pm 0.12 \\
0.27[0.23 ; 0.31] \pm 0.19 \\
0.0381^{*}\end{array}$ & $\begin{array}{c}0.0108^{*} \\
0.3294\end{array}$ \\
\hline
\end{tabular}

PPD - mean value of probing pocket depth at 6 measurement points ( $M B, B, D B, M L, L, D L)$; PPDb - mean value of probing pocket depth on buccal surfaces at 3 measurement points $(M B, B, D B) ; C A L-$ mean value of clinical attachment level at 6 measurement points $(M B, B, D B, M L, L, D L)$;

CALb - mean value of clinical attachment level on buccal surfaces at 3 measurement points (MB, B, DB); GRD - mean value of gingival recession depth; GRDred - mean value of gingival recession depth reduction; KTW - mean value of keratinized tissue width; KTWgain - mean value of gain in keratinized tissue; FMPI - full mouth plaque index; PS - plaque score at lower incisors; FMBOP - full mouth bleeding on probing score; BOP - bleeding on probing score at lower incisors; $p$ for intragroup comparison; \#p for intergroup comparison; * statistically significant at $p \leq 0.05$.

Table 3. Changes in clinical parameters (mean, 95\% Cl, SD) at the lower incisors at the mid-buccal point over time in the study groups

\begin{tabular}{|c|c|c|c|c|c|c|}
\hline Variables & Baseline & 3 months & 6 months & 12 months & p1 & $\begin{array}{l}\text { p2 baseline } \\
-12 \text { months }\end{array}$ \\
\hline PPD mid-buccal [mm] & $1.25[1.17 ; 1.33] \pm 0.45$ & $1.19[1.12 ; 1.26] \pm 0.39$ & $1.17[1.10 ; 1.24] \pm 0.38$ & $1.17[1.10 ; 1.24] \pm 0.38$ & 0.4235 & 0.1662 \\
\hline CAL mid-buccal [mm] & $3.20[2.84 ; 3.55] \pm 1.94$ & $2.65[2.27 ; 3.03] \pm 2.09$ & $2.23[1.87 ; 2.59] \pm 1.98$ & $2.00[1.67 ; 2.34] \pm 1.81$ & 0.3241 & $<0.0001^{*}$ \\
\hline GR mid-buccal [mm] & $2.09[1.76 ; 2.41] \pm 1.78$ & $1.78[1.45 ; 2.10] \pm 1.79$ & $1.41[1.11 ; 1.71] \pm 1.65$ & $1.22[0.95 ; 1.48] \pm 1.46$ & $0.0147^{*}$ & $0.0005^{*}$ \\
\hline KTW mid-buccal [mm] & $2.24[2.05 ; 2.43] \pm 1.06$ & $2.49[2.29 ; 2.68] \pm 1.06$ & $3.04[2.82 ; 3.26] \pm 1.19$ & $3.42[3.18 ; 3.66] \pm 1.29$ & $0.0078^{*}$ & $0.0002^{*}$ \\
\hline
\end{tabular}

Mean value of probing pocket depth (PPD) at the mid-buccal point (B), mean value of clinical attachment level (CAL) at the mid-buccal point (B), mean value of gingival recession depth (GRD), mean value of keratinized tissue width (KTW); p1 for comparison of changes at 4 time points (baseline, 3 months, 6 months, 12 months); p2 for comparison of differences between baseline and 12 months; ${ }^{*}$ statistically significant at $p \leq 0.05$.

with gingival augmentation procedures with FGG, and observed a $4.2 \mathrm{~mm}$ increase in KTW and a $0.8 \mathrm{~mm}$ gingival margin shift 10 years after surgery. ${ }^{32}$ Furthermore, $18-$ 35 years after treatment, $83 \%$ of augmented sites showed gingival recession reduction, whereas $48 \%$ of untreated sites showed increased recession. ${ }^{33}$ The reported keratinized tissue augmentation with FGG varied from $3.1 \mathrm{~mm}$ to $5.6 \mathrm{~mm}$. Limitations associated with FGG include 
mucogingival junction misalignment as well as poor color and texture match with neighboring tissues. ${ }^{5,6}$ For these reasons, FGG utilization should be thoroughly evaluated, especially in cases involving the anterior region of the maxilla or mandible. Several disadvantages of FGG have been overcome by the use of subepithelial connective tissue grafts (SCTG). ${ }^{34}$ They are considered the gold standard in mucogingival surgery, but also have some disadvantages. The surgery requires a $2^{\text {nd }}$ operation to obtain the donor tissue from the palate, the amount of donor tissue is limited, and the procedure significantly increases complications and pain due to the need to surgically open a $2^{\text {nd }}$ site to obtain the donor tissue..$^{5,11,19,20}$ Vestibuloplasty does not aim to increase the width of the gingival keratinized structure either, as it is the case with FGG, since it is determined by cells at the genetic level and the grafted palatal tissue is keratinized. ${ }^{36}$ It is noteworthy, however, that in the 12-month observation period the keratinized gingival zone increased in the test group at the incisors; by contrast, in the control group, KG remained at a similar level or decreased slightly. The results in the test group, which were based on clinical probing, should be treated with caution due to the absence of histological examination of the relevant tissue. It is difficult to conclusively determine if the procedure itself reduced recession or if it occurred due to changes in the patients' oral hygiene practices (all patients switched to the roll tooth brushing technique). Reduction of gingival recession and increase of the attached gingiva zone may have been caused by the resolution of gingival inflammation following elimination of pulling of marginal gingiva and proper oral hygiene. It is likely that elimination of pulling restores proper function of keratinizing cells within the free gingiva and enables reconstruction of the keratinized gingiva zone previously reduced by the inflammatory process. ${ }^{1,36}$ It may support the already postulated observation that elimination of gingival margin pulling restores the conditions for proper functioning of keratinizing cells within the free gingiva. The results also indicate that the elimination of pulling and resolution of marginal gingivitis enabled reconstruction of clinical attachment.

According to Ward, however, it appears that satisfactory periodontal and gingival health can be maintained even where the vestibule is shallow. ${ }^{4}$ Moreover, the findings demonstrate that it is possible to maintain periodontal health and attachment through control of gingival inflammation despite the absence of attached gingiva. ${ }^{37}$ On the other hand, more recent studies have shown that narrow gingiva in combination with a shallow vestibular fornix might promote the accumulation of food debris during mastication and impede proper oral hygiene. Hence, vestibular deepening should be considered when patients experience discomfort while brushing and chewing. Changes in tooth brushing habits may be of greater importance than increased gingival thickness for long-term maintenance of the surgically established position of the soft tissue margin. ${ }^{38}$

The results of this study revealed changes in the presence of plaque and bleeding in the test group. Decreased plaque and bleeding may be due to the creation of better conditions for maintaining oral hygiene as well as frequent follow-up visits (every 3 months in the 12-month observation period), creating an opportunity to reinforce oral hygiene instructions. In the control group, in which patients only received follow-up after 12 months, relevant oral hygiene parameters did not improve. Wade also reported a correlation between plaque scores and vestibule depth when carrying out the deepening of the vestibule according to the Edlan and Mejchar technique. ${ }^{39}$ He concluded that it is a reliable technique and maintains gingival health in the case of a limited amount of gingival tissue on the labial aspect of the mandibular anterior teeth.

The apically positioned flap (APF) technique seems to be a simple and cost-effective procedure that does not involve a secondary donor site and supplemental biomaterials. Lim et al. reported a KTW of $3.24 \pm 1.12 \mathrm{~mm} 6$ months after surgery which decreased to $2.11 \pm 0.69 \mathrm{~mm}$ after 12 months, as well as higher scores for contour and texture compared to FGG-treated sites. ${ }^{25}$ Carnio et al. described a modified apically repositioned flap (MARF) technique without donor areas or the use of commercial products. ${ }^{40}$ This approach involved a single horizontal incision within keratinized tissue, preparation of a split-thickness flap, and its suturing to the periosteum in the apical position. The exposed periosteum healed by secondary intention, resulting in a significant increase in KTW from $2.14 \mathrm{~mm}$ to $4.24 \mathrm{~mm}$. The reported values are greater than those in our study, but they might be explained by different surgical protocols.

Commercially available ADM yielded inferior outcomes to FGG in terms of obtained KTW and tissue thickness, but that the esthetic results and color match were superior. Wei et al. reported statistically smaller keratinized tissue increases for ADM-treated sites than FGG-treated sites $(2.59 \pm 0.92 \mathrm{~mm}$ compared to $5.57 \pm 0.44 \mathrm{~mm}) .{ }^{23} \mathrm{Mu}-$ cograft is a non-cross-linked porcine bilayer collagen matrix (CM) composed of pure type I and III collagen, which was also shown to increase KTW. ${ }^{24,25}$ The CTG attained a mean KTW of $2.6 \pm 0.9 \mathrm{~mm}$, while CM attained $2.5 \pm 0.9 \mathrm{~mm}, 6$ months after surgery. DynaMatrix is obtained from the submucosa of the small intestine of pigs and is a cell-free matrix where the natural matrix molecules are preserved. Thirteen months after surgical intervention, sites treated with DynaMatrix showed an increased KTW of $2.6 \pm 1.1 \mathrm{~mm}$ compared to $5.3 \pm 1.3 \mathrm{~mm}$ of KTW gain as a result of augmentation with autogenous gingival graft. $^{26}$

In our study, apart from the gain in keratinized tissue, we also observed GRD reduction and CAL gain that were beneficial from a clinical point of view. We speculate that, due to optimizing plaque control and eliminating pulling 
syndrome, the proper function of keratinized cells within free gingiva was restored, which enabled reconstruction of keratinized tissues previously reduced by the inflammatory process. Even if the observed changes were small compared to those achieved by previously described techniques, some patients may still benefit from the modified Kazanjian procedure to facilitate plaque control and optimize periodontal health. Such surgery might be more critical for elderly patients, as well as for patients who, for whatever reason - financial or psychological - do not agree to more advanced surgery. In the surgical protocol of this study, patients were prescribed antibiotic prophylaxis for 3 days after the procedure. It can be assumed that taking antibiotics is not necessary after this type of surgery. However, we presented a consecutive group of first operated patients and did not change the protocol until the end of the study.

\section{Limitations}

Our research has some limitations. First and foremost, the study is not randomized. Thus, accidental bias, including selection bias, is present. The study groups were formed according to patients' preferences. It would be ethically questionable to purposefully prevent individual patients from receiving treatment. Moreover, the baseline condition of the patients in the present study was not statistically comparable, as controls had a lower amount of KTW. Thus, this is another shortcoming of a non-randomized study. However, the mean KTW value accounted for the labial surfaces of all mandibular incisors and the inclusion criterion was at least 1 tooth with $\mathrm{KTW} \leq 1 \mathrm{~mm}$. The difference may stem from a greater number of teeth with more severely reduced KTW in the controls. Nevertheless, the observed increase in KTW 12 months after treatment in the test group was statistically significant. Even though these issues are important and deserve recognition, we believe that the outcomes of our study might be helpful for practitioners, since there is a gap between protocols being widely investigated and those carried out in clinical practice.

Secondly, although we observed improvement in CAL measurements, it should be stressed that the woundhealing process presumably resulted in the development of long junctional epithelium and not real regeneration. To evaluate the true nature of healing, histological analysis needs to be carried out. Furthermore, the CAL results suggest that the creeping attachment phenomenon may have occurred in the test group on teeth with gingival recession. As mentioned above, the reason for this may be better condition (more space) for the roll tooth brushing technique to be performed.

Thirdly, patient-reported outcomes were not collected. Such data should be included in future studies. The postsurgical course of events, patients' discomfort and pain, esthetic outcomes, and patients' general satisfaction with the treatment modality should be taken into account. In light of these facts, there is an obvious need for further long-term, well-designed clinical trials with a larger sample size to verify the present findings. Future research should focus on alternative approaches that improve treatment outcomes while also being less invasive and time-consuming and more cost-effective.

\section{Conclusions}

Within the limitations of our study, it can be concluded that modified Kazanjian vestibuloplasty is a simple method that increases KTW and improves periodontal health at buccal aspects of the lower incisors. This procedure may be recommended for patients for whom an increase in KTW, reduction in muscle pull and frena elimination are desired, but surgical palatal trauma must be avoided, as well as for patients who do not want to be submitted to a secondary surgical procedure at the palate.

\section{ORCID iDs}

Beata Wyrębek (1) https://orcid.org/0000-0001-9977-0125 Renata Górska (10 https://orcid.org/0000-0002-2769-7587 Katarzyna Gawron (1) https://orcid.org/0000-0003-0937-4749 Małgorzata Nędzi-Góra (1) https://orcid.org/0000-0003-4041-2678 Bartłomiej Górski (1) https://orcid.org/0000-0002-3918-4332 Paweł Plakwicz (1) https://orcid.org/0000-0003-4713-2142

\section{References}

1. Schmid M, Mormann W, Bachman A. Mucogingival surgery: The subperiosteal vestibule extension. Clinical results 2 years after surgery. J Clin Periodontol. 1979;6(1):22-32. doi:10.1111/j.1600-051x.1979.tb0 2287.x

2. Mehta P, Peng L. The width of the attached gingiva: Much ado about nothing? J Dent. 2010;38(7):517-525. doi:10.1016/j.jdent.2010.04.007

3. Cortellini P, Bissada NF. Mucogingival conditions in the natural dentition: Narrative review, case definitions, and diagnostic considerations. J Clin Periodontol. 2018;89(Suppl 1):S204-S213. doi:10.1002/ JPER.16-0671

4. Ward VJ. The depth of the vestibular fornix in the mandibular anterior region in health. J Periodontol. 1976;47(11):651-655. doi:10.1902/ jop.1976.47.11.651

5. Zucchelli G, Marzadori M, Mounssif I, Mazzotti C, Stefanini M. Coronally advanced flap + connective tissue graft techniques for the treatment of deep gingival recession in the lower incisors: A controlled randomized clinical trial. J Clin Periodontol. 2014;41(8):806-813. doi:10. 1111/jcpe.12269

6. Kim DM, Neiva R. Periodontal soft tissue non-root coverage procedures: A systematic review from the AAP regeneration workshop. J Periodontol. 2015;86(Suppl 2):S56-S72. doi:10.1902/jop.2015.130684

7. Clark HB. Deepening the labial sulcus by mucosal flap advancement: Report of a case. J Oral Surg. 1953;11(2):165-168. PMID:13035574

8. Friedman N. Mucogingival surgery: The apically repositioned flap. J Periodontol. 1962;33(4):328-340. doi:10.1902/jop.1962.33.4.328

9. Edlan A, Mejchar B. Plastic surgery of vestibulum in periodontal therapy. Int Dent J. 1963;13:593. doi:10.1111/j.1600-0765.1969.tb01984

10. Tortorelli AF. A technique for vestibular sulcus extension. J Prosthet Dent. 1968;20(1):14-20. doi:10.1016/0022-3913(68)90208-4

11. Thoma DS, Benić GI, Zwahlen M, Hämmerle CHF, Jung RE. A systematic review assessing soft tissue augmentation techniques. Clin Oral Implants Res. 2009;20(Suppl 4):146-165. doi:10.1111/j.1600-0501.2009. 01784.x

12. Kazanjian VH. Surgery as an aid to more efficient service with prosthetic dentures. J Am Dent Assoc. 1935;22(4):566-581. doi:10.7860/ JCDR/2016/16606.7192 
13. Kiernicka M, Owczarek B, Gałkowska E, Wysokińska-Miszczuk J. Reduction of gingival recessions as unplanned additional effect of surgical procedures of the oral vestibule. Annales Universitatis Mariae Curie-Skłodowska, Lublin. 2007; LXII, N 1, 23, D.

14. Wyrębek B, Górska R, Nędzi-Góra M, Plakwicz P. Effect of vestibular deepening on the periodontal status of teeth: Preliminary study. J Stoma. 2016;69(5):531-537. doi:10.5604/00114553.1230107

15. Al-Mahdy ABF. Mandibular anterior ridge extension: A modification of the Kazanjian vestibuloplasty technique. J Oral Maxillofac Surg. 1997;55(10):1057-1059, discussion 1060. doi:10.1016/s0278-2391(97) 90278-0

16. Ponzoni D, Jardim EC, de Carvalho PS. Vestibuloplasty by modified Kazanjian technique in treatment with dental implants. J Craniofac Surg. 2013;24(4):1373-1375. doi:10.1097/SCS.0b013e3182860524

17. Liposky RB. Elimination of the "V" in vestibuloplasty. J Oral Maxillofac Surg. 1983;41(5):339-340. doi:10.1016/0278-2391(83)90304-x

18. Wyrębek B, Orzechowska A, Plakwicz P. Vestibular deepening using the modified Kazanjian technique. A case report. TPS. 2016;1-2:42-47.

19. Chambrone L, Tatakis DN. Periodontal soft tissue root coverage procedures: A systematic review from the AAP Regeneration Workshop. J Periodontol. 2015;86(Suppl 2):S8-S51. doi:10.1902/jop.2015.130674

20. Zucchelli G, Mele M, Stefanini M, et al. Patient morbidity and root coverage outcome after subepithelial connective tissue and deepithelialized gingival grafts: A comparative randomized-controlled clinical trial. J Clin Periodontol. 2010;37(8):728-738. doi:10.1111/j.1600051X.2010.01550.x

21. Wessel JR, Tatkis DN. Patient outcomes following subepithelial connective tissue graft and free gingival graft procedures. J Periodontol. 2008;79(3):425-430. doi:10.1902/jop.2008.070325

22. Grzech-Leśniak K, Matys J, Jurczyszyn K, et al. Histological and thermometric examination of soft tissue de-epithelialization using digitally controlled Er:YAG laser handpiece: An ex vivo study. Photomed Laser Surg. 2018;36(6):313-319. doi:10.1089/pho.2017.4413

23. Wei PC, Laurell L, Geivelis M, Lingen MW, Maddalozzo D. Acellular dermal matrix allografts to achieve increased attached gingiva. Part 1. A clinical study. J Periodontol. 2000;71(8):1297-1305. doi:10.1902/jop. 2000.71.8.1297

24. Sanz M, Lorenzo R, Aranda JJ, Martin C, Orsini M. Clinical evaluation of a new collagen matrix (mucograft prototype) to enhance the width of keratinized tissue in patients with fixed prosthetic restorations: A randomized prospective clinical trial. J Clin Periodontol. 2009;36(10):868-876. doi:10.1111/j.1600-051X.2009.01460.x

25. Lim HC, An SC, Lee DW. A retrospective comparison of three modalities for vestibuloplasty in the posterior mandible: Apically positioned flap only vs. free gingival graft vs. collagen matrix. Clin Oral Investig. 2018;22(5):2121-2128. doi:10.1007/s00784-017-2320-y
26. Nevins M, Nevins ML, Camelo M, Camelo JM, Schupbach P, Kim DM. The clinical efficacy of DynaMatrix extracellular membrane in augmenting keratinized tissue. Int J Periodontics Restorative Dent. 2010; 30(2):151-161. PMID:20228974

27. Kaya Y, Alkan O, Keskin S. An evaluation of the gingival biotype and the width of keratinized gingiva in the mandibular anterior region of individuals with different dental malocclusion groups and levels of crowding. Korean J Orthod. 2017;47(3):176-185. doi:10.4041/ kjod.2017.47.3.176

28. O'Leary TJ, Drake RB, Naylor JE. The plaque control record. J Periodontol. 1972;43(1):38. doi:10.1902/jop.1972.43.1.38

29. Ainamo J, Bay I. Problems and proposal for recording gingivitis and plaque. Int Dent J. 1975;25(4):229-235. PMID:1058834

30. Miller PD. A classification of marginal tissue recession. Int J Periodontics Restorative Dent. 1985;5(2):8-13. PMID:3858267

31. Cairo F, Nieri M, Cincinelli S, Mervelt J, Pagliaro U. The interproximal clinical attachment level to classify gingival recessions and predict root coverage outcomes: An explorative and reliability study. J Clin Periodontol. 2011;38(7):661-666. doi:10.1111/j.1600-051X.2011.01732.x

32. Agudio G, Nieri M, Rotundo R, Cortellini P, Pini Prato G. Free gingival grafts to increase keratinized tissue: A retrospective long-term evaluation (10 to 25 years) of outcomes. J Periodontol. 2008;79(4):587-594. doi:10.1902/jop.2008.070414

33. Agudio G, Cortellini P, Buti J, Pini Prato G. Periodontal conditions of sites treated with gingival augmentation surgery compared with untreated contralateral homologous sites: An 18- to 35-year longterm study. J Periodontol. 2016;87(12):1371-1378. doi:10.1902/jop. 2016.160284

34. Langer B, Langer L. Subepithelial connective tissue graft technique for root coverage. J Periodontol. 1985;56(12):715-720. doi:10.1902/ jop.1985.56.12.715

35. Zucchelli G, Mounssif G. Periodontal plastic surgery. Periodontol 2000. 2015;68(1):333-368. doi:10.1111/prd.12059

36. Karring $T$, Lang NP, Loe $\mathrm{H}$. The role of gingival connective tissue in determining epithelial differentiation. J Periodontal Res. 1975;10(1): 1-11. doi:10.1111/j.1600-0765.1975.tb00001.x

37. Kennedy JE, Bird WC, Palcanis KG, Dorfman HS. A longitudinal evaluation of varying widths of attached gingiva. J Clin Periodontol. 1985; 12(8):667-675. doi:10.1111/j.1600-051x.1985.tb00938.x

38. Wennström JL, Zucchelli G. Increased gingival dimensions: A significant factor for successful outcome of root coverage procedures? A 2-year prospective clinical study. J Clin Periodontol. 1996;23(8): 770-777. doi:10.1111/j.1600-051x.1996.tb00608.x

39. Wade AB. Vestibular deepening by the technique of Edlan and Mejchar. J Periodontal Res. 1969;4(4):300-313. doi:10.1111/j.1600-0765.1969. tb01984.x

40. Carnio J, Miller PD Jr. Increasing the amount of attached gingiva using a modified apically repositiones flap. J Periodontol. 1999;70(9):1110-1117. doi:10.1902/jop.1999.70.9.1110 